\title{
LA POLÉMICA DE LA TEOLOGÍA POLÍTICA Y SU VIGENCIA ACTUAL
}

\section{THE CONTROVERSY OF THE POLITICAL THEOLOGY AND ITS CURRENT VALIDITY}

\author{
DESIDERIO PARRILLA MARTÍNEZ \\ Universidad Católica San Antonio de Murcia
}

Recibido: 17/09/2018

Aceptado: 23/01/2019

\section{RESUMEN}

En el mundo Post 11-S asistimos a un resurgir de la teología política como fenómeno mundano y académico. Las discusiones actuales retoman esta disciplina en unos términos muy similares a los utilizados en la década de 1970 en la polémica sobre la "liquidación de la teología política", donde participaron los principales expertos de filosofía política internacional. En este artículo exponemos los argumentos fundamentales de aquella discusión, a fin de mostrar las aportaciones que esta polémica clásica podría ofrecer a la situación geopolítica actual. En primer lugar, desarrollaremos el debate según su estructura argumental siguiendo las intervenciones de los protagonistas de la disputa y sus antecedentes históricos. A continuación, mostraremos cómo se puso de manifiesto que la teología política no sólo precedía a la tradición cristiana, sino que también formaba parte de la filosofía moderna. Concluiremos mencionando la recuperación de la disciplina que algunos autores proponen en el contexto geopolítico actual.

Palabras clave: Ética, teología política, religión, filosofía política 


\section{ABSTRACT}

In the Post 11-S world we witness a resurgence of political theology as a mundane and academic phenomenon. The current discussions take up this discipline in very similar terms to those used in the 1970s in the controversy over the "liquidation of political theology", in which the mean experts on international political philosophy participated. In this article we expose the fundamental arguments of that discussion, in order to show the contributions that this classic polemic could offer to the current geopolitical situation. In the first place, we will develop the debate according to its argumentative structure, following the interventions of the protagonists of the dispute and its historical antecedents. Next, we will show how it became clear that political theology not only preceded the Christian tradition but was also part of modern philosophy. We conclude by mentioning the recovery of the discipline that some authors propose in the current geopolitical context.

Keywords: Ethics, political theology, religion, political philosophy.

\section{INTRODUCCIÓN: RESURGIR ACTUAL DE LA “TEOLOGÍA POLÍTICA”}

En el panorama geopolítico posterior al 11S la teología política ha recuperado plena vigencia (Mathewes 2010). Incluso puede decirse que esta actualidad ha repercutido con igual o mayor intensidad en el ámbito académico ${ }^{1}$. Las monografías, artículos y publicaciones en general son abundantes y manifiestan el gran interés científico que esta disciplina despierta tanto fuera como dentro de la universidad (Phillips 2012; Hovey, Cavanaugh y Bailey 2011; O’Donovan, 1999). El examen de esta realidad es asumido también por los principales estados soberanos para determinar sus estrategias de política internacional, tanto militares como jurídicas y diplomáticas (Sullivan 2009; Linker 2007). Sin embargo, el interés práctico por la teología política se encuentra sostenido por una labor de reflexión muy anterior a la actual coyuntura internacional.

Fue la recuperación de la teología política en la primera mitad del siglo XX la que estableció el marco general de la disciplina (Lefort 2006). El intento por

1 En el ámbito anglosajón cabe destacar la labor divulgativa emprendida desde 2011 por "Political Theology Today" cuyos responsables David True y Vincent Lloyd editan desde 1999 la revista científica con índice de impacto "Political Theology". En esta institución se recensionan las principales publicaciones, congresos y encuentros internacionales consagrados al estudio de la teología política en todo el mundo. Sirve como aglutinante para los principales investigadores, fundaciones, instituciones privadas y think tanks, así como los debates académicos de la disciplina. Por su parte la prestigiosa editorial Bloomsbury abrió en 2003 una sección dedicada específicamente a la publicación de libros sobre nuestra disciplina. 
parte de Carl Schmitt de rehabilitar el viejo proyecto hegeliano de la teología política como disciplina científica (Hegel 2004, 114-223; Shanks 2008; Negro 2011, 439-472) tuvo una consecuencia ambivalente, ya que favoreció el desarrollo de la disciplina y su estudio académico, pero este desarrollo desembocó en la acumulación de aporías y contradicciones que actualmente se esgrimen en contra de la propia teología política como disciplina. Las discusiones que prosiguieron en torno a estas dificultades durante la segunda mitad del siglo XX en el ámbito franco-germánico constituyeron una matriz muy fértil para generar nuevas doctrinas de teología política, pero no se mostró tan capaz a la hora de ofrecer un marco general que se viera libre de las aporías.

Sin embargo, la famosa polémica en torno a la "liquidación de la teología política" (Zarka 2008, 27-47; Navarrete Alonso 2015, 63-75) puso de manifiesto la necesidad de recuperar la disciplina por razones estrictamente prácticas, pese a su posible limitación teórica. La razón de esta necesidad no era un regreso a formas arcaicas previas a la ilustración o el estado moderno secularizado, sino la necesidad de fortalecer ese estado laico desde formas de teología política que consiguiesen fortalecer unas instituciones seculares que no podían ser fortalecidas institucionalmente de ninguna otra manera. La polémica manifestó las condiciones en que esa teología política podía cumplir con este cometido estrictamente técnico.

El resultado del debate concluía que era necesario obtener una formulación de la teología política como disciplina sistemática a fin de salvaguardar instituciones como la sociedad civil o el estado político. En el presente artículo ofrecemos una exposición de los principales episodios de esta controversia que nos permiten entender su relevancia en la coyuntura geopolítica actual. Los hallazgos obtenidos en aquella polémica mantienen su vigencia y pueden servir para resolver algunos de los problemas geopolíticos más acuciantes de nuestra época.

\section{LA CONTROVERSIA SOBRE LA IMPOSIBILIDAD DE UNA TEOLO- GÍA POLÍTICA}

Tradicionalmente se establece la crítica de Agustín de Hipona a la "teología civil" de Marco Terencio Varrón (116-27 a. de C.) como el origen de la "teología política" como disciplina. En su "Ciudad de Dios" (libro VI, capítulo V) Agustín expone la "teología tripartita" de Varrón: religión natural (genus physikon), religión civil (genus politikon) y religión mítica (genus mythikon), referentes a la divinización de los procesos naturales, de las divinidades del estado y el panteón mitológico, respectivamente (Lieberg 1982, 25-53; Kany 2000, 1434-1435). 
Para Varrón la teología política remite a la dimensión política de la religión tradicional romana en cuanto supone una religión imperial (Boyancé 1972, 253282). San Agustín recusó esta teología política o civil. La teología política resulta para San Agustín una superstición incompatible con la fe cristiana, pues identificaba la teología mítica y la política (O’Daly 1996, 65-75). La teología política, en consecuencia, perdía su rango epistemológico de ciencia, aunque la propuesta alternativa del propio San Agustín originó el "agustinismo político" (Arquillière 2005) que incurría en el mismo defecto al poner la teología política al servicio de la elaboración de una forma política de signo contrario.

La obra de San Agustín puede ser interpretada, en cierto sentido, como una respuesta a "La República" de Cicerón, según la cual la Ciudad de Dios sirve de opción frente al "Sueño de Escipión" y la Iglesia ofrece su cumplimiento a la Res Publica (García Alonso 2009, 197-219; Velásquez 2001, 527-538). Si Varrón sometía la religión al estado, Cicerón fundaba el estado en la piedad religiosa. Ambos coincidían en elaborar una teología política cuyo objeto es la construcción de una forma política más que construir una teología política que tiene por objeto el estudio de las ideas políticas trabadas con las ideas teológicas. Agustín en "La Ciudad de Dios" se limitaría a privilegiar la opción de Cicerón frente a la de Varrón. De este modo la teología política de Agustín no superaba las limitaciones de la teología política de Varrón o de Cicerón, sino que se limitaba a tomar partido, reinterpretando y sustituyendo una doctrina por otra. Sin embargo, esta disputa ofreció la primera manifestación de una teología política cuyo objeto directo fue el estudio de las ideas políticas en su confluencia con las ideas teológicas y no tanto la construcción de formas políticas en relación con la teología.

Desde que Carl Schmitt reintrodujo el término "teología política" en 1922 el término ha cobrado la fuerza de un tecnicismo, aunque su posibilidad como disciplina no ha dejado de ser puesta en cuestión. En la primera mitad del siglo XX Carl Schmitt retomó expresamente el término "teología política" en su crítica a la República de Weimar, recibiendo el apoyo del canonista católico Hans Barion y el teólogo Karl Eschweiler. El seguidor de Carl Schmitt, Hans Hirt, definió así su proyecto de teología política: "el apoyo de decisiones políticas o estructuras estatales con categorías teológicas de pensamiento y la justificación de su pretensión de poder y dominio" (Hirt, 1938, p. 325). Numerosas polémicas surgieron contra la propuesta de Carl Schmitt a partir de las objeciones dirigidas por Erik Peterson y su crítica teológica a la relación entre monarquía y monoteísmo (Peterson 1999). Pero cuando la cuestión teopolítica parecía ya periclitada, Johannes Bauptist Metz elaboró una Nueva Teología Política en la segunda mitad del siglo XX como réplica al "catolicismo político" de Carl Schmitt bajo 
la influencia de los teólogos luteranos Jürgen Moltmann y Wolfrang Pannenberg (Darschin 1969, 302-317).

Este resurgir contemporáneo de la teología política sin embargo estaba lastrado por las limitaciones tradicionales que encontramos en San Agustín. La teología política no alcanzaba el estatuto de una disciplina sistemática. Las diversas propuestas se limitaban a ser ensayos de sucesivas formas políticas en combinación con la religión. Más que una disciplina (científica o filosófica) con un campo delimitado propio, la teología política se conformaba con expresar una propuesta de ciertas formas políticas frente a otras formas políticas alternativas (Fiorenza 2012, 142-177; Van Wyk 2015, 1-8; György 2005, 31-61).

Hans Maier (Friburgo, 1931), siendo profesor de ciencias políticas en la universidad de Múnich acusó a Metz de ignorar el trasfondo histórico de la discusión sobre la expresión "teología política" cuando presentó su proyecto con este título ${ }^{2}$. Para Maier no es casual la elección de este término que recubre los diversos modelos de identificación entre la sociedad eclesiástica y las formas socio-políticas. En un movimiento pendular Metz sólo reiteraba el impulso que Carl Schmitt pretendió otorgarle, aunque promoviendo un tipo de politización de la Iglesia de signo contrario (Maier 1970, 16-22). Hans Maier considera que entre la vieja teología política recuperada por Carl Schmitt y la nueva teología política fundada por Johann Bauptist Metz no existe una diferencia sustancial. Ambas se parecen cuando aquella identifica el pasado histórico de la teología con una ideología política, mientras esta coloca el término de la identificación en un futuro indeterminado (Maier 1970, 26). Sin embargo, para Maier ambos intentos de fundar una teología política son ilegítimos dado que la teología política es imposible desde la tradición cristiana según lo dejó establecido san Agustín en "La Ciudad de Dios" (Maier 1991, 33-46; Maier 2007). La polémica acerca de la "liquidación de cualquier teología política" estaba presentada en sus términos generales.

En 1970, el año álgido de su polémica con Metz, Hans Maier fue nombrado Ministro de Educación y Cultura de Baviera por el partido conservador de la Unión Social Cristiana, puesto que ocupó hasta 1987 por desavenencias con el entonces primer ministro y miembro de su partido Franz Josef Strauß. Inmerso en la teología política de los partidos de la Democracia Cristiana europea Hans Maier postula en la discusión un dualismo, o diarquía de poderes, donde se

2 Hans Maier escribió dos artículos de 1969 y 1970 atacando la teología política de Metz: "Politische Theologie? Eiwände eines Laien", Stimmen der Zeit, 94: 73-91, y "Noch einmal: Politische Theologie", Stimmen der Zeit, 95: 145-171. Ambos han sido reimpresos en su monografía: Hans Maier. 1970. Kritik der politischen Theologie. Einsiedeln: Johannes-Verlag. 
sanciona una ruptura entre la esfera de lo religioso y la del compromiso sociopolítico. Desde este planteamiento Maier insistía en el origen no cristiano de toda teología política, olvidando que él mismo practicaba una teología política sin saberlo: "Desde un punto de vista cristiano, en ella se trata de una teologización ilegítima de formas existentes del estado o de la sociedad; se trata de su transfiguración religiosa (...) en el sentido de una recíproca penetración de lo estatal y lo divino, del culto y la política" (Maier 1970, 116).

Al identificar el término teología política con este modelo teórico de interpenetración de los contenidos sacro-religiosos bajo la estructura de las relaciones sociopolíticas, Hans Maier podía concluir que todo proyecto de teología política es ilegítimo desde la perspectiva cristiana. Pero este punto de vista incurría para Carl Schmitt en una petición de principio pues presuponía lo que aún quedaba por demostrar, a saber, que el concepto en discusión pueda reducirse exclusivamente al tipo de estructura política que Maier condenaba de antemano. El círculo vicioso se agravaba cuando Maier formulaba el argumento a través de un dialelo que partía del presupuesto de que esa tesis es condenable para concluir con su inapelable condenación. Su crítica a la "teocracia de extrema izquierda" de Metz (o al "cesaropapismo de extrema derecha" de Schmitt) la emprende Maier desde la potestad indirecta de la teocracia mediata, moderada, pero capitalista y neoliberal, que las Democracias Cristianas abanderaron en Europa desde la posguerra. Denunciar esta aporía fue la estrategia utilizada por el teólogo Ernst Feil para reducir al absurdo los argumentos de Hans Maier.

Ernst Feil (1932-2013), teólogo católico que en 1962 se convirtió en profesor adjunto de Johann Baptist Metz en Teología Fundamental en la Universidad de Münster de Westfalia (Alemania), intervino en favor de su maestro en la polémica con Hans Maier ofreciendo una interesante reflexión histórica de la expresión "teología política" que ha resultado clave en el desarrollo de la disciplina. Su pretensión era refutar la tesis de Maier según la cual el cristianismo clausuraba la posibilidad misma de la teología política (Feil 1969, 110-132; Pozo 1971, 123-128). La reconstrucción histórica en cuestión arrojó tres conclusiones fundamentales:

1) es verdad como afirma Hans Maier que la expresión "teología política" tiene un origen previo e independiente del cristianismo, porque la teología política cristiana constituye sólo una parte de la historia total de la teología política universal;

2) no se puede legitimar teóricamente el rechazo de toda teología política identificándola con un solo tipo histórico, porque la relación entre religión y 
política no es unívoca, ya que existen numerosos tipos de religiones y numerosos tipos de políticas y, por tanto, numerosos tipos de correlaciones entre ellas;

Y finalmente 3) Hans Maier incurre en una paradoja: la disociación radical entre lo religioso no político y lo político no religioso permite juzgar las manifestaciones históricas y obtener conclusiones universalmente verdaderas. De esta manera hemos establecido un campo de saber que permite obtener conclusiones verdaderas sobre la teología política, aunque sólo sea para refutarla.

Paradójicamente, con esta tercera conclusión, Hans Maier anulaba desde la teología cristiana una realidad política, como es la teología política. Pero al hacerlo, Maier desbordaba los límites que él mismo se había fijado. Porque estaba emitiendo un juicio político a partir de premisas teológicas. Estaba haciendo, por tanto, teología política. Ese campo de saber desde el cual juzga algunos tipos de teología política, en suma, es la teología política sistemática que se está buscando. Parafraseando a Étienne Gilson podemos concluir que la teología política suele enterrar a sus sepultureros.

Para escapar a esta paradoja Hans Maier afirmaba que toda despolitización de la teología política sería en todo caso una política teológica, pero nunca una teología política. De esta manera Maier entroncaba con la conclusión a la que antes arribó Hans Barion, el seguidor de Carl Schmitt, en su violenta polémica anti-modernista con la teología del concilio Vaticano II. Barion desempeñó la labor como co-editor de la publicación "Epirrhosis" en conmemoración del 80 cumpleaños de Carl Schmitt en 1965. En esta etapa Barion asume la derrota del “catolicismo político" y la "vieja teología política" de su maestro Carl Schmitt, pero se revuelve contra las pretensiones de la Nueva Teología Política de Metz que considera una crítica teológica de la religión política. La expresión "religión política" responde para Barion y para Moltmann con lo que Metz llama la "vieja teología política". También critica las tesis de los democristianos, conservadores y liberales católicos por politizar la Iglesia desde la derecha. Barion admite la teología como despolitización teológica de la Iglesia y esta teología política es la única libre de toda decisión política intramundana. Barion en política sólo concede a la Iglesia un derecho histórico de afinidades tácticas, que puede oscilar entre la derecha y la izquierda. Pero no existe un campo legítimo de relación de la Iglesia con la política, excepto la intervención por transgresión grave de principios morales (ratione peccati). Para no traicionar su misión divina la Iglesia no puede privilegiar a alguna de las muchas formas políticas posibles que no contradicen los "diez mandamientos" (Barion 1968, 54).

Para Hans Barion la historia de la Iglesia romana como manantial de un poder político supone un desarrollo ilegítimo. Entre la esfera de la sociedad 
religiosa y la esfera de la sociedad política sólo cabe un vínculo sub ratione peccati. Esta despolitización de la Iglesia por parte de Barion presupone su tesis de que entre ambos poderes se da una conjunción armónica propia de una teocracia mediata. A su vez esta despolitización se opone, según Barion, a dos procesos de politización de la Iglesia: A) la teología política, que denota los procedimientos mediante los cuales la teología ejerce su derecho de juzgarlo todo, extendiendo su crítica hasta el campo político y B) la política teológica, que denomina los procedimientos mediante los cuales una sociedad estatal emplea argumentos teológico-eclesiales para justificar sus programas (Barion 1968, 14). El primero puede desembocar en la teocracia o el cesaropapismo; el segundo se reduce a la fatalidad del cesaropapismo. Tanto uno como otro proceso de politización puede ponerse al servicio de la teocracia o el cesaropapismo.

De esta manera Hans Barion considera clausurada la cuestión de si una teología política es posible concluyendo que tal teología política sería ilegítima, por ser ajena a la tradición eclesiástica, o simplemente inexistente. El error de Barion consiste en olvidar que la teocracia mediata en la que él mismo se desenvuelve es una teología política del mismo rango que el cesaropapismo o la teocracia inmediata que combate con sus argumentos.

Como podemos comprobar, en la estela de Hans Barion surgieron las propuestas posteriores acerca de la liquidación de esta disciplina, representadas por Hans Maier, Hans Albert, Robert Spaemann y Ernst Topitsch. En su crítica a la "Nueva teología política" de Metz, Hans Maier afirmaba que después de Cristo cualquier proyecto de teología política es ilegítimo. Esta ilegitimidad afecta por igual al cesaropapismo y a la teocracia, en cualquiera de sus formas históricas de antiguo y nuevo régimen (Mainer 1970, 18-19).

Ernst Topitsch (1919-2003) desde el neo-positivismo funda su refutación del estado universal establecido en clave teopolítica según las tesis de Erik Peterson e invocando la autoridad de San Agustín de Hipona en unos términos semejantes a los de Hans Maier. Pese a estar conforme con la liquidación de la teología política como cesaropapismo, Topitsch incoa una propuesta de teología política general y sistemática donde establece correlaciones verticales y horizontales de la institución política con las imágenes religiosas. La conexión entre un ámbito y otro puede ser de tipo sociomorfo, biomorfo o tecnomorfo. Esta clasificación sistemática no suministra una explicación sobre su conexión, pero avanza una primera catalogación que ordena los fenómenos que nos encontramos dentro de nuestro campo de estudio (Topisch 1955, 19-30).

Por lo demás, la posición de estos autores refleja un punto de vista ampliamente compartido por los teólogos. El mismo discurso se encuentra en Bertrand 
Julian de Clercq cuando sigue la exégesis de G. Bornkamm sobre Mc 12, 17 (Clercq 1970, 127-128). Más recientemente, el esquema dicotómico de Hans Barion se reitera en Máximo Borguesi para concluir que no puede existir teología política cristiana (Borghesi 2009, 165-186). De este mismo razonamiento depende la precaución del lenguaje empleada por Pierre Manent cuando utiliza el rótulo "problema teológico-político" en lugar de "teología política" (Manent 1987, 19-20). La perífrasis del "problema teológico-político" fue la fórmula canónica utilizada por Leo Strauss como lugar clave de su estudio de la ambivalencia de los textos greco-romanos de filosofía política en su conexión con la religión. También es el núcleo de su propuesta de la tensión entre lo exotérico y lo esotérico de cualquier investigación política de naturaleza filosófica posterior (Meier 2006, 31-88; Hernando Nieto 2002, 177-187).

Para Leo Strauss la filosofía política y la teología política resultan inseparables en cuanto ambas disciplinas se fundan en último término en preguntas históricas básicas como: “¿qué es la vida justa?”, “¿qué es lo bueno?” y, en definitiva, "quid sit deus?" Carl Schmitt y Julien Freund se equivocaron al caracterizar la naturaleza de lo político, pues la noción política fundamental no es la oposición amigo-enemigo, sino el binomio bueno-malo que posibilita cualquier relación de oposición y alianza, llegando a considerar lo bueno y lo malo de manera absoluta, hasta alcanzar la consideración de lo que es absolutamente bueno y lo que es absolutamente malo sin excepción. En este punto de la reflexión radical la filosofía política conecta necesariamente con la teología política. Pero se establece simultáneamente un dilema, pues se debe decidir entre dos opciones diametralmente opuestas: o bien considerar que al hombre le basta la sola razón y su voluntad natural para alcanzar el conocimiento y la práctica de lo radicalmente bueno o, por el contrario, optar por la posición que considera que lo radicalmente bueno lo concede Dios mediante la gracia de una Revelación.

Sin embargo, el decisionismo de Leo Strauss no genera una disyuntiva radical donde ambos caminos (lo natural o lo sobrenatural) se alejen el uno del otro, o incluso lleguen a oponerse mutuamente como incompatibles. La decisión que se origina en el seno del dilema es pragmática y no pretende disolver el dilema en favor de una de las dos opciones, a costa de sacrificar la otra opción. Se elija lo uno o lo otro, no podrá ser contra lo uno o contra lo otro. Optar por la filosofía política implica optar por la teología política, y viceversa. La decisión se mantiene como discurso esotérico subyacente al discurso exotérico que se emite. Este secreto que abraza el dilema entre filosofía y teología política es el secretum cordis de la filosofía de Leo Strauss: una filosofía política que no renuncia a beneficiarse de la tolerancia y alianza tácita con la teología política 
del signo que sea, mientras garantice la supervivencia de la república, según el magisterio de Maquiavelo.

El llamado "dilema de Böckenförde" 3 no es sino disolver esta ambivalencia contenida en el "problema de la teología política" planteado por Leo Strauss y trasladar lo problemático hacia el terreno de la filosofía política, sustituyéndolo por "el problema de la filosofía política" (Große Kracht 2014, 91-121). Böckenförde manifiesta el debilitamiento moral de las sociedades liberales y la amenaza que esta debilidad supone para su supervivencia (Böckenförde, 2007). Böckenförde no propone un rearme teológico político de cariz teocrático que salvaguarde las maltrechas sociedades liberales en franca decadencia. Más bien disuelve la ambivalencia que Leo Strauss inyecta al dilema de la modernidad y reclama la recuperación unívoca, explícita y sin rodeos del polo teopolítico, tanto para explicar el debilitamiento que se sigue de su abandono por parte de las sociedades liberales secularizadas como para favorecer el fortalecimiento de las mismas a través de su recuperación y colaboración expresa con la filosofía política (Kreß 2006, 243-258).

\section{RECUPERACIÓN DE LA TEOLOGÍA POLÍTICA EN LA CONTRO- VERSIA DE 1970}

La crítica de Ernst Feil logró desbloquear este tópico que habitualmente se retrotrae a san Agustín de Hipona para legitimar teológicamente el rechazo de la teología política. Como Feil trata de demostrar Hans Maier apela al magisterio agustiniano para promover la liquidación de la teología política en el siglo XX, tanto contra Carl Schmitt como contra Johann Bauptist Metz. Hans Maier se apoya en la autoridad del Padre de la Iglesia latina para insistir en el origen no cristiano de la teología política. Reconoce el tópico de que la expresión "teología política" es anterior al cristianismo y que aparece ya en Varrón y su división ternaria de la teología. Pero este recurso a "La Ciudad de Dios" de san Agustín resulta improcedente (Feil 1969, 116). Enst Feil pone de relieve con una densa reconstrucción histórica que el rechazo de la expresión y de cualquier teología

3 El asunto del estatuto de la teología política moderna se reavivó cuando el jurista Ernst-Wolfgang Böckenförde se planteó las condiciones del estado que el estado mismo no puede producir por sí mismo (el llamado "dilema de Böckenförde"). La Doctrina Böckenförde se considera "el centro de la Liberalkonservativismus". Esas condiciones pre-estatales, indispensables para la supervivencia del estado, están dadas religiosamente. Así entendida, la tarea de la teología política reside en establecer las condiciones indispensables de la política mediante una reflexión teológica y una crítica académica. Este dilema fue el núcleo del debate entre Jünger Habermas y Benedicto XVI: (Habermas y Ratzinger 2006). 
política siempre constituye un acto político decidido desde una teología política alternativa.

Como Feil pone de manifiesto en su estudio, san Agustín comenta esta división de Varrón admitiendo que la teología mítica corresponde a las representaciones poéticas de la divinidad, la teología natural a las representaciones filosóficas y la teología política a los ritos, cultos y ceremonias del estado. La teología civil constituye la religión civil y pública. Fueran cuales fuesen las convicciones privadas quien ponía en duda los postulados de la teología política era considerado como falto de civismo y enemigo del estado. El ateísmo era un atentado contra el estado tanto más que contra Dios. En este contexto ha de entenderse la acusación de ateísmo lanzada contra los cristianos de los primeros siglos en el imperio romano. Pero en este punto del análisis Feil insiste en que san Agustín no pretende oponerse a esta teología política romana sino contrarrestar el argumento tomado de la teología política de los romanos según la cual la invasión de Roma por los bárbaros obedecía a la decadencia de las costumbres romanas, en parte por la introducción de posiciones similares a la fe cristiana que rompía con el culto público e introducía división interna en el imperio. Agustín demuestra exactamente lo contrario, que la fe cristiana retoma el heroísmo moral romano y lo fortalece a través de un nuevo culto. De esta manera no se es mal ciudadano ni se debilita el poder del estado por no participar del viejo culto de la religión civil romana, porque el nuevo culto lo fortalecía en mayor medida que el antiguo. La intervención de Agustín no se dirige contra la teología política romana ni contra la teología política en general. Por esta razón el cristianismo posterior adoptó sin problemas el modelo político-religioso inherente a la teología política romana.

Según Ernst Feil, Maier se equivoca cuando acude a San Agustín para reivindicar la fe cristiana como contraria a la teología política, cuando lo cierto es que Agustín posibilita la construcción de la misma como algo connatural a la tradición cristiana. La contribución de San Agustín dio cuerpo a una determinada estructura de las relaciones socio-políticas con la Iglesia, sancionada como auténtica teología política. Aunque esta modalidad no es la única posibilidad en exclusiva que la teología política puede adoptar, como pone de manifiesto la historia posterior, el hecho atestigua que la teología política transita desde el paganismo a la cristiandad sin solución de continuidad. Con independencia de las múltiples formas de teología política que se adopte el cristianismo cimienta directamente la civilización posterior. La cristianización de la religión pública romana otorga al cristianismo el vínculo con el supremo poder político durante la edad media, disputándoselo o no a los sucesivos imperios (Moltmann 1973, 21-22; Moltmann 1987, 15-52). 
Esto sucedió también en los inicios de la modernidad y en la época de la ilustración cuando se tomó partido a favor de la teología natural, o la religión natural, contra la teología política imperante en Europa. Con la instauración de la Reforma protestante no se suspendió la teología política anterior, sino que mutó adoptando nuevas formas según el adagio cuius regio eius et religio. Los promotores de la "religión natural" (Bodino, Grocio, Leibniz) tampoco anulan la teología política, sino que proceden a una nueva metamorfosis a partir de los modelos precedentes. En este sentido el siglo de las luces multiplica y complica los tipos de teología política en lugar de reducirlos, simplificarlos o extinguirlos. La relación de la sociedad religiosa con la sociedad política adquiere formas novedosas y esta proliferación -a veces exponencial- complica los modos de trabar las dimensiones políticas y religiosas. El contenido crítico de la teología política cambia de cometido y se hace más amplio al tomar en consideración todas las partes en conflicto. Los modelos de teología política crecen en número hasta el punto que los modelos no establecen dicotomías sino múltiples dicotomías simultáneas. Esto obliga a tener una visión sinóptica de conjunto de todos los tipos en conflicto para poder tomar partido o mudar de una posición a otra. Cuando se considere esta totalidad de forma sistemática al margen de todo interés práctico o estratégico habrá nacido la teología política como disciplina teórica con campo propio. El siglo de las luces fue, por tanto, una suerte para la teología política sistemática.

En la época moderna las motivaciones se hacen más políticas que religiosas y se recupera la vieja noción de "religión civil" o "teología civil" de Varrón, pero planteada en unos términos religiosos procedentes de la "teología natural" ilustrada. Rousseau empleó el término "religión civil" en el capítulo VIII del libro IV de su obra "El Contrato Social" (1762), para distinguir los principios religiosos vinculantes para los cristianos de aquellos otros principios civiles que atañen a todos los ciudadanos de un Estado. Estos persiguen la subsistencia del pacto social y garantizan la cohesión social. Gottfried Wilhelm Leibniz operó con el concepto del "cultus civilis" en su proyecto teológico político de reunificar las diversas confesiones cristianas contra el Imperio Otomano. Immanuel Kant desarrolló una forma de la religión secular: la religión natural, como religión dentro de los límites de la mera razón. El historiador italiano Emilio Gentile estudió los orígenes y el despliegue del concepto y propuso la contraposición entre una religión civil y una religión política (Gentile 2006). Robert N. Bellah y Martin E. Marty consideran que esta "religión civil" (Bellah 1967, 1-21) o "teología pública" (Marty 1989, 295) está en el origen y en la esencia política de los Estados Unidos. 
En la modernidad tampoco faltarán las facciones de teología política que se ponen al servicio de un orden socio-político ya establecido o que se quiere restaurar. Para Feil esta tendencia de signo político conservador de las relaciones entre religión y política se consolidó, por ejemplo, en las obras de Tomás Hobbes y Nicolás Maquiavelo (Feil 1969, 121; Assmann 1973, 11-12). Fueron las corrientes del romanticismo conservador en Alemania y del tradicionalismo francés del siglo XIX las que basadas en el rechazo de la alianza entre el cristianismo y el principio de la libertad (o tolerancia religiosa) propio de la Revolución francesa, pusieron la teología política al servicio de la restauración del Antiguo Régimen. Pero la misma teología política restauradora se basaba también en una crítica de la sociedad, negándole la posibilidad de la reforma religiosa, la revolución política o cualquier medida progresista según los esquemas del Nuevo Régimen.

Será el impacto que cause la obra de Carl Schmitt la que identifique la "teología política" en general con este caso especial de "teología política" que es la "teología política reaccionaria". La teología política de la corriente tradicionalista utilizó esta expresión para designar el empleo de principios teológicos para legitimar decisiones políticas, formas de estado o reivindicaciones a favor de los poderes establecidos. El ascendente ejercido por Carl Schmitt permitió que esta facción contra-revolucionaria secuestrara el título de "teología política" ejercitándolo en exclusiva y negando a otros su titularidad (Feil 1969, 125). Según Ernst Feil la equivocación de Hans Maier reside en asumir acríticamente esta identificación. Para Feil la teología política que pretende instaurar la alianza entre lo sagrado y el poder es la "vieja teología política", mientras que la "nueva teología política" de su maestro Metz designa el esfuerzo de reflexión crítica sobre las relaciones de la fe cristiana con la sociedad.

Finalmente, Feil se hace eco de la polémica de Erik Peterson con Carl Schmitt para recuperar la "teología política" frente a Hans Maier. Erik Peterson, teniendo presente el sentido que Carl Schmitt otorga al término "teología política", propone en su estudio sobre el monoteísmo como problema político la tesis de que el dogma teológico de la Trinidad hace imposible la identificación monárquica de lo sagrado con el poder político (Peterson 1999, 27-65). Peterson llega a la conclusión de la ilegitimidad cristiana de cualquier "teología política". Hans Maier retiene de este escrito la prueba de que el evangelio cristiano no puede funcionar teológicamente como legitimación de poderes y programas políticos. Por tanto, concluye Hans Maier, "la historia cristiana de la teología política no puede ser otra que la historia de su destrucción" (Maier 1970, 36). Lo esencial de la teología política sería entonces este procedimiento destructivo, no los contenidos positivos que podría albergar. La "teología política" de Metz 
contraviene esta conclusión cuando Metz admite que la "teología política" posee un campo de estudio propio capaz de obtener conclusiones positivas.

Feil considera que la obra de Peterson, demostrando la especificidad de la religión cristiana a partir del dogma trinitario, serviría sólo en el contexto de la teología política alemana para refutar la Reichtheologie de Carl Schmitt. No serviría, por tanto, para rechazar la "teología política" como disciplina teórica ni para rechazar todos los modelos de teología política generados a lo largo de la historia universal, dado que Erik Peterson y Hans Maier razonan desde un modelo de teología en particular, a saber, el dualismo teocrático de la potestad indirecta (Feil 1969, 126). La obra de Peterson puede considerarse como un ejemplo de política teológica, pero no resuelve todavía el problema de la teología política, que subsiste con plena vigencia sin verse afectado por sus críticas. Feil asume las críticas que Carl Schmitt dirigió posteriormente a Erik Peterson y que pueden resumirse en tres puntos:

1) El programa de liquidación de toda teología política se apoya en la obra de Erik Peterson, un estudio circunscrito exclusivamente al binomio monoteísmo-monarquía durante los primeros trescientos años de cristiandad. Este estudio resulta excesivamente simplista y no considera el asunto en su toda su complejidad. Pero además existe una desproporción entre los resultados de la encuesta y el alcance universal de la conclusión. La desproporción es aún más inaceptable cuando no se atiende a la teología política ajena al cristianismo, presente en otras culturas o períodos históricos, o no se atiende a sus antecedentes en las religiones políticas o el mecanismo genético que las origina.

2) La denuncia de Erik Peterson dirigida contra la teología política estaría funcionando como mito que explica con razones ahistóricas hechos históricos y descarga a sus adeptos de un examen más riguroso. La metodología empleada por Peterson no resulta adecuada para el objeto material de estudio que reclama un objeto formal diferente, aunque se pretendieran alcanzar las conclusiones destructivas deseadas. Incluso aunque se aspirase a destruir el campo de la teología política la perspectiva adoptada por Erik Peterson tampoco sería la perspectiva adecuada.

3) El éxito de la leyenda de la ilegitimidad de la teología política procede no de una verdad teórica sino de una política pragmática de propaganda y hechos consumados. La teología política de Peterson se reconoce como válida y se elogia como sagrada en las democracias liberales posteriores a la II Guerra Mundial porque se opuso a la teología política del partido nacional-socialista de Adolf Hitler. Peterson no liquidó ni la teología política en general ni la teología política de Carl Schmitt en concreto. Los ejércitos aliados impusieron sus diversas 
teologías políticas, recubriendo las aniquiladas teologías políticas de las Potencias del Eje, sólo después de haberlas arruinado militar y económicamente. Pero eso no convierte en verdadera la tesis de Peterson en modo alguno ni la libra de su condición de leyenda, más bien recrudece su condición de mito por razones políticas y teológicas, usado en favor de las triunfantes democracias liberales que gestionan políticos como Hans Maier.

Sólo a la luz de la antítesis teológico-jurídico tiene un sentido científico preciso la proposición: el monoteísmo político ha sido liquidado teológicamente. ¿Cómo puede una teología que de manera categórica se desliga de la política liquidar teológicamente a una eminencia o una pretensión políticas? Si teológico y político son dos ámbitos de contenidos separados -distintos toto caelo, entonces una cuestión política sólo puede ser liquidada políticamente (Schmitt 2009, 119).

\section{CONCLUSIÓN: LA VIGENCIA DE LA TEOLOGÍA POLÍTICA EN LA ACTUALIDAD}

Los acontecimientos posteriores a la caída de la URSS desmintieron que hubiéramos entrado en el "Fin de la historia" y devolvieron la "teología política" al centro de la palestra geopolítica, saltando desde las cátedras a la vida cotidiana de las democracias occidentales. La teocracia chiíta en la República Islámica de Irán o el rearme del islam salafista en Afganistán parecían sucesos aislados y sostenidos por la guerra proxy entre Estados Unidos la Unión Soviética. Pero el "efecto bumerán" que supuso la facción talibán, Al Qaeda y los atentados del $11 \mathrm{~S}$, pusieron de relieve la generalización de un proceso global en creciente desarrollo que no ha hecho sino agravarse con la creación del Daesh y su proyecto de Estado Islámico universal (Hallaq 2009).

Las sucesivas "primaveras árabes" manifestaron este equilibrio inestable de fuerzas en toda la media luna del panarabismo donde la destrucción del socialismo islámico, último residuo de la guerra fría, no ha generado espontáneamente el capitalismo democrático que se invocaba al legitimar las intervenciones en oriente próximo. Los valores meta-políticos dominantes en las democracias occidentales, acompañan acciones militares, diplomáticas y de espionaje de gran alcance geoestratégico. Esta coyuntura geopolítica pone de manifiesto la importancia de la teología política como componente de la capa meta-política del estado, según dejó delineado Leo Strauss en la controversia de 1970. Compete a la academia la labor de retomar la reflexión de estas cuestiones decisivas, a fin de no caer en una sucesión de errores contrarios (Lilla, 2007). 
Como hemos mostrado, la recuperación de la teología política en 1970 no trataba de tomar como pretexto los problemas meta-políticos de los estados para imponer una teología política sobrevenida y ajena a los valores de la cultura occidental y la ilustración europea. Por el contrario, aspiraba a encontrar el engranaje teológico político necesario para salvaguardar y fortalecer estos mecanismos meta-políticos que en la actualidad han entrado gravemente en crisis. Regresar a la polémica suscitada en los años 70 acerca de esta espinosa cuestión, resulta imprescindible para resolver desde ella, ahora en un contexto muy diferente, el "dilema de Böckenförde", suscitado entonces: "The liberal, secularised state is nourished by presuppositions that it cannot itself guarantee" (Böckenförde 1991, 45). Será en el seno de esta discusión racional y académica donde las democracias occidentales podrán encontrar la fórmula teo-política adecuada. Para algunos autores sólo la teología política nacida de la Humanitas greco-romana, transmitida por la cultura cristiana y potenciada por la Ilustración europea devolvería sus raíces a las actuales formas políticas occidentales (Habermas y Ratzinger, 2006).

\section{REFERENCIAS BIBLIOGRÁFICAS}

Andrew Sullivan, A. 2009. The Conservative Soul: The Politics of Human Difference. Nueva York: Harper Collins.

Arquillière, Henri-Xavier. 2005. El agustinismo politico. Ensayo sobre la formación de las teorías políticas en la Edad Media. Granada: Universidad de Granada.

Assmann, Hugo. 1973. Teología desde la práxis de la liberación. Salamanca: Sígueme.

Barion, Hans. 1968. "Weltgeschichtliche Machtform? Eine Studie zur Politischen Theologie des II. Vatikanischen Konzils". En: Epirrhosis: Festgabe C. Schmitt, 13-59. Berlin: Duncker \& Humblot.

Bellah, Robert N. 1967. "Civil Religion in America", Daedalus, 96, no 1: 1-21. Böckenförde, Ernst-Wolfgang. 1991. State, Society and Liberty: Studies in Political Theory and Constitutional Law. New York: Berg.

—. 2007. "Der säkularisierte Staat. Sein Charakter, seine Rechtfertigung und seine Probleme im 21. Jahrhundert". En: Themenband 86 der Carl Friedrich von Siemens Stiftung. München: Carl Friedrich von Siemens Stiftung.

Borghesi, Maximo. 2009. "Da Peterson a Ratzinger: Agostino e la critica alla teologia política". En: Ritorno alla religione, V. Possenti (ed.), 165-186. Milano: Guerini \& Associati. 
Boyancé, Pierre. 1972. "Sur la théologie de Varron”, Publications de l'École française de Rome, $11 \mathrm{n}^{\mathrm{o}}$ 1: 253-282.

Clercq, Bertrand Julian. 1970. Religion, ideología y política. Salamanca: Sígueme.

Darschin, Wolfgang. 1969. "Bibliographische Hinweise zur politischen Theologie". En: Helmut Peukert (ed.), Diskussion zur politische Theologie, 302317. Mainz-München: Matthias Grünwald.

Feil, Ernst. 1969. "Von der politischen Theologie zur Theologie der Revolution?" En: Diskussion zur “Theologie der Revolution”, Feil, E. y Weth, R. (ed.), 110-132.Munich: Maguncia.

Fiorenza, Francis. 2012. "Political theology as foundational theology". Proceedings of the catholic theological society of America, 32: 142-177.

García Alonso, Marta. 2009. "La Ciudad de Dios como alternativa al Sueño de Escipión. Los primeros pasos de la teología política cristiana”. Pensamiento. Revista de Investigación e Información Filosófica, 65, no 244: 197-219.

Geréby, György. 2005. "Carl Schmitt and Erik Peterson on the Problem of Political Theology. A footnote to Kantorowicz". En: Monotheistic Kingship. The Medieval Variant, János M. Bak, Aziz al-Azmeh (eds.), 31-61. Budapest: CEU Press.

Große Kracht, Hermann-Josef. 2014. "Fünfzig Jahre Böckenförde-Theorem. Eine bundesrepublikanische Bekenntnisformel im Streit der Interpretationen". En: Religion - Recht - Republik. Studien zu Wolfgang-Ernst Böckenförde, Große Kracht, H.-J. y K. (eds.), 91-121. Paderborn: Schöningh. Hallaq, Wael B. 2009. Sharia: Theory, Practice, Transformations. Cambridge: University Press.

Hegel, Georg Wilhelm Friedrich. 2004. Lecciones sobre la filosofia de la historia universal. Madrid: Alianza.

Hernando Nieto, Eduardo. 2002. “¿Teología Política o Filosofía Política?: La amistosa conversación entre Carl Schmitt y Leo Strauss". Foro Jurídico, no 1: $177-187$.

Hirt, Hans. 1937. "Monotheismus als politischen Problem?” Hochland 35.

Hovey, Craig, Cavanaugh, William y Bailey Jeffrey W. 2010. An Eerdmans Reader in Contemporary Political Theology. Michigan: Eerdmans.

Kany, Roland. 2000. "Theologia tripartite". En: Lexikon für Theologie und Kirche, Bd. 9, Kasper, Walter (ed.), 1434-1435. Freiburg: Verlag.

Lefort, Claude. 2006. "The Permanence of the Theologico-Political?" En: Political Theologies: Public Religions in a Post-Secular World, Vries, E. y Sullivan, E. L. (eds.), 148-188. New York: Fordham University Press.

Lieberg, Godo. 1982. "Die theologia tripartita als Formprinzip antiken Denkens". Rheinisches Museum 125: 25-53. 
Lilla, Mark. 2007. The Stillborn God: Religion, Politics, and the Modern West. New York: Knopf.

Linker, Damon. 2007. The Theocons. New York: Knopf Doubleday Publishing Group.

Maier, Hans. 1970. Kritik der politischen Theologie. Einsiedeln: Johannes-Verlag.

-. 1991. "Erik Peterson und das Problem der politischen Theologie". Zeitschrift für Politik: 33-46.

Manent, Pierre. 1987. Histoire intellectuelle du liberalisme. París: CalmannLévy.

Marty, Martin E. 1989. Religion and Republic: The American Circumstance. Boston: Beacon Press.

Mathewes, Charles. 2010. The Republic of Grace: Augustinian Thoughts for Dark Times. Michigan: Eerdmans.

Meier, Heinrich. 2006. Leo Strauss y el problema teológico-político. Buenos Aires: Katz.

Moltmann, Jürgen. 1973. "Crítica teológica de la religión política”. En: Ilustración y teoría teológica. La Iglesia en la encrucijada de la libertad moderna. Aspectos de una nueva teología política, Metz, J. B. y Moltmann J. y Oelmüller, W., 21-22. Salamanca: Sígueme.

—. 1987. Teología política, ética política. Salamanca: Sígueme.

Navarrete Alonso, Roberto. 2015. "Teología política y Modernidad: Peterson, Blumenberg y Schmitt", Daimon. Revista Internacional de Filosofia, $\mathrm{n}^{\circ}$ 65: 63-75.

Negro, Dalmacio. 2011. "La teología política de Hegel”. En: Historia del análisis político, Pablo Sánchez Garrido (coord.), 439-472. Madrid: Tecnos.

O’Daly, Gerard JP. 1996. "Augustine's Critique of Varro on Roman Religion", En: Religion and Superstition in Latin Literature, Alan Sommerstein (ed.), 65-75. Bari: Levante editori.

O'Donovan, Oliver. 1999. The Desire of the Nations: Rediscovering the Roots of Political Theology. Cambridge: CUP.

Peterson, Erik. 1999. El monoteísmo como problema politico. Barcelona: Trotta. Phillips, Elizabeth. 2012. Political Theology: A Guide to the Perplexed. Oxford: T\&T Clark.

Pozo, Candido. 1971. "Teología política”. En: Iglesia y secularización, Danielou, J. y Pozo, C. (eds.), 123-128.Madrid: BAC.

Ratzinger, Joseph y Habermas, Jünger. 2006. Dialéctica de la secularización. Sobre la razón y la religión. Madrid: Encuentro.

Sánchez Barbosa, Diana Marcela. 2016. "Cicerón y Agustín. A propósito de la república”, Universitas philosophica, Vol. 33, nº. 67: 201-215. 
Schmitt, Carl. 2009. Teología política. Madrid: Trotta.

Shanks, Andrew. 2008.Hegel's Political Theology. Cambridge: CUP.

Topitsch, Ernst. 1955. "Kosmos und Herrschaft. Ursprünge der politischen Theologie", Wort und Wahrheit, $\mathrm{n}^{\mathrm{o}}$ 1: 19-30.

Van Wyk, Tanya. 2015. "Political Theology as critical theology". HTS Theological Studies, vol. 71, no 3: 1-8.

Velásquez, Óscar. 2001. "Cicerón en el De civitate Dei de San Agustín: las complejidades de un diálogo". Anuario Filosófico, 34: 527-538.

Zarka, Yves-Charles. 2008. "Para una crítica de toda teología política”. Isegoría. Revista de Filosofía Moral y Política, no 39: 27-47.

Desiderio Parrilla Martínez

Departamento de Humanidades

Universidad Católica San Antonio de Murcia (UCAM)

Av. de los Jerónimos, 135

30107, Guadalupe, Murcia (España)

https://orcid.org/0000-0001-7203-5630 
